\title{
Effects of Curcumin in Combination with Doxorubicin in Human Colorectal Cancer Cell Line
}

\author{
Zakieh Rostamzadeh Khameneh ${ }^{1}$, Mahshid Mohammadian², Mohammad Aziz \\ Rasouli $^{3}$, Zhino Moradi ${ }^{4}$, Zohre Ahmadi ${ }^{5}$, Azim Akbarzadeh Khiyavi ${ }^{6}$
}

${ }^{1}$ Solid Tumor Research Center, Urmia University of Medical Sciences, Urmia, Iran. ${ }^{2}$ Department of Medical Laboratory Sciences, School of Allied Medical Sciences, Urmia University of Medical Sciences, Urmia, Iran. ${ }^{3} \mathrm{MSc}$ in Epidemiology, Vice Chancellor for Educational and Research, Kowsar Hospital, Kurdistan University of Medical sciences, Sanandaj, Iran. ${ }^{4}$ Medical Physic Department, Faculty of Medicine, Urmia University of Medical Sciences Urmia, Iran. ${ }^{5} \mathrm{MSc}$ student of health education and health promotion,faculty of health, Qom university of medical sciences ,Qom, Iran. ${ }^{6}$ Department of Pilot Nanobiotechnology, Pasteur Institute of Iran, Tehran, Iran.

\begin{abstract}
Background: Colorectal cancer (CRC) is one of the main cause of cancer related death worldwide. New therapeutic strategies are required for CRC. Anthracycline drugs such as doxorubicin (DOX) remain one of the most active wide-spectrum and cost-effective drugs in cancer therapy. However, colorectal cancer (CRC) cells are inherently resistant to anthracyclines. Curcumin, the active component and yellow pigment, has been considered as anti-cancer agents with anti-proliferation, anti-invasion, and anti-angiogenesis properties. Previous data show that curcumin may played main role as therapeutic agent for CRC. We aimed to assess the possible sensitizing effects of curcumin in HCT-116 CRC cells treated with DOX. Methods: HCT-116 cells were treated with different doses of curcumin and DOX in increasing concentrations and cytotoxicity were evaluated after 48 $\mathrm{h}$ by Water Soluble Tetrazolium Salts(WST-1) method. In double combination treatments ( $48 \mathrm{~h}$ ), the mentioned concentration were utilized; D ( Curcumin; $20 \mu \mathrm{M} ; \mathrm{DOX} ; 5 \mu \mathrm{M}$ ) C (Curcumin; $10 \mu \mathrm{M} ; \mathrm{DOX} ; 2.5 \mu \mathrm{M}$ ), B (Curcumin; $5 \mu \mathrm{M} ; \mathrm{DOX} ; 1 \mu \mathrm{M}$ ) and A (Curcumin; $2.5 \mu \mathrm{M} ; \mathrm{DOX} ; 0.5 \mu \mathrm{M}$ ). Results: HCT-116 cells treatments with various concentrations of single agents (DOX and curcumin) decreased the cellular viability in a dose-dependent pattern. Here, we show that treatment of HCT-116 CRC cells with curcumin increases the efficacy of DOX-induced death in HCT-116 cells. Curcumin treatments also results in higher cytotoxicity of DOX and the cell death percent in compared to higher doses in single treatments. Conclusion: It could be concluded that curcumin could acts as chemosensitiser towards the DOX therapy. So it might be used as adjuvant therapy to enhance DOX sensitivity in CRC cells.
\end{abstract}

Keywords: Colorectal cancer- curcumin- doxorubicin

\section{Introduction}

Colorectal cancer (CRC) is one of the main leading causes of cancer related mortality worldwide [1]. Although the patients survival has recently increased due to improved surgery, local radiotherapy and chemotherapy, but the high rate of metastatic patients prognosis are not good [1-2]. Indeed, one of the main goals in cancer therapy is to predict response to chemotherapeutic drugs by drug response assays [3]. Anthracycline drugs including doxorubicin
(DOX) considered as furthermost active wide-spectrum and Inexpensive drugs in cancer treatment. However, CRC cells are characteristically resistant to anthracyclines [4]. Indeed cancer cells shows resistance toward anti-cancer agents in major cases [1-2]. On the other hands, numerous routine chemotherapeutics have adverse side effects; dietary manipulations might have an important role in the prevention of numerous human cancers. Curcumin the yellow pigment in turmeric has been extensively utilized in the Asian countries [5]. Previous data has been revealed that curcumin prevent the growing of transformed cells

Corresponding Author:

Mahshid Mohammadian

Department of Medical Laboratory Sciences, school of Allied Medical Sciences, Urmia University of Medical Sciences, Urmia, Iran.

Email: Mohammadian_mahshid1365@yahoo.com 
and colon carcinogenesis at the beginning and progression phases in carcinogen-induced models [6-7]. We aimed to evaluate the possible sensitizing effects of curcumin in HCT-116 CRC cells treated with DOX.

\section{Materials and Methods}

\section{Cell lines and Cell Cultures}

Human HCT-116 cells were purchased from the Pasteur Institute (Tehran, Iran). Cells were maintained in growth medium consisting of Dulbecco's modified Eagle's medium [DMEM (BioWest, France)] supplemented with $10 \%$ fetal bovine serum (FBS) and $1 \%$ antibiotic (BioWest, France) at $37^{\circ} \mathrm{C}$ and $5 \% \mathrm{CO}_{2}$. Cells were passaged utilizing trypsin/EDTA. Curcumin was purchased from Sigma Chemical Co. (USA), dissolved in $100 \%$ ethanol, and then diluted with the DMEM. Doxorubicin hydrochloride purchased from sigma-Aldrich (USA) and solubilized in pure water.

\section{Treatments and Cellular Viability Assay}

Cells were treated with curcumin and DOX (viability in response to curcumin and DOX was assessed by WST-1 after $48 \mathrm{~h}$. Briefly, cells were dispersed by trypsin-EDTA treatment and $1 \times 10^{4}$ cells $/ \mathrm{ml}$, re-suspended in DMEM containing $10 \%$ FBS and seeded into 96-wells culture plates with 3 replicates. After 24 h of plating, treatments was performed for $48 \mathrm{~h}$ in the absence (control) or presence of $\operatorname{DOX}(1,2.5,5,10,20$ and $40 \mu \mathrm{M})$ and curcumin $(10,20,50,75$ and $100 \mu \mathrm{M})$ in single treatments. The concentration of double combination were as below in A to E groups.

D ( Curcumin; $20 \mu \mathrm{M} ; \mathrm{DOX} ; 5 \mu \mathrm{M}$ ) C ( Curcumin; 10 $\mu \mathrm{M}$; DOX ; $2.5 \mu \mathrm{M}$ ), B (Curcumin; $5 \mu \mathrm{M} ; \mathrm{DOX} ; 1 \mu \mathrm{M}$ ) and A (Curcumin; $2.5 \mu \mathrm{M}$; DOX; $0.5 \mu \mathrm{M}$ ).

The E group (control) considered as control which include the untreated cells had any exposure to DOX and curcumin.

At the end of the $48 \mathrm{~h}$ incubation period, the reaction was terminated by adding $10 \mu \mathrm{l}$ of WST- 1 stock to each well. The reaction was allowed to proceed for $3-4$ hours at $37^{\circ} \mathrm{C}$. Cell viability was assayed according to the cleavage of the tetrazolium salt, water-soluble tetrazolium-1 (WST-1), to dark red formazan. Absorbance was read at $420 \mathrm{~nm}$ with a reference wavelength $>650$ using the enzyme-linked immunosorbent assay microplate reader. All values were compared to the related controls. All assays were performed with triple replicates.

\section{Statistical analysis}

Data shown as the mean \pm SD. The differences among more than two means were evaluated by one-way analysis of variance (ANOVA) with SPSS software, V. 10.0 (SPSS Inc, Chicago, Illinois). $\mathrm{P}<0.05$ considered as significance level.

\section{Results}

\section{Effects of DOX on cell viability}

The cytotoxic effects of the single treatments of DOX and curcumin after $48 \mathrm{~h}$ of exposure in CRC cell line plotted as the percentage of viable cells versus control cells (Figure 1). As presented in Figure 1, the exposure of HCT-116 cells to various concentrations of single agents (DOX and curcumin) decreased the cellular viability in a dose-dependent pattern.

Cytotoxic effects of DOX in combination with curcumin on HCT-116 cells

Different concentrations of DOX in combination with curcumin were selected according to the initial tests mentioned in the methods to evaluate the cytotoxic effects of drug combinations on the HCT-116 cell line.

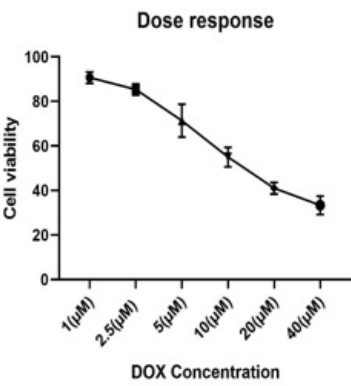

(A)

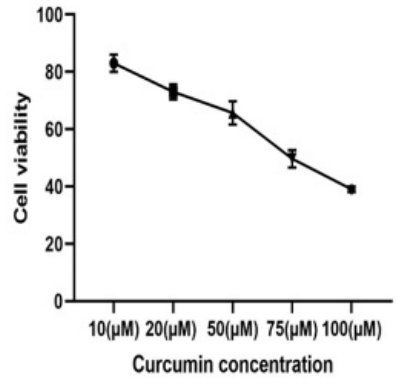

(B)
Figure 1. Dose Response Curve of DOX (A) and Curcumin (B) Treatments in HCT-116 Cells in the Concentrations of $1,2.5,5,10,20$ and $40 \mu \mathrm{M}$ of DOX and $10,20,50,75$ and $100 \mu \mathrm{M}$ of Curcumin; DOX, doxorubicin $(\mu \mathrm{M})$.

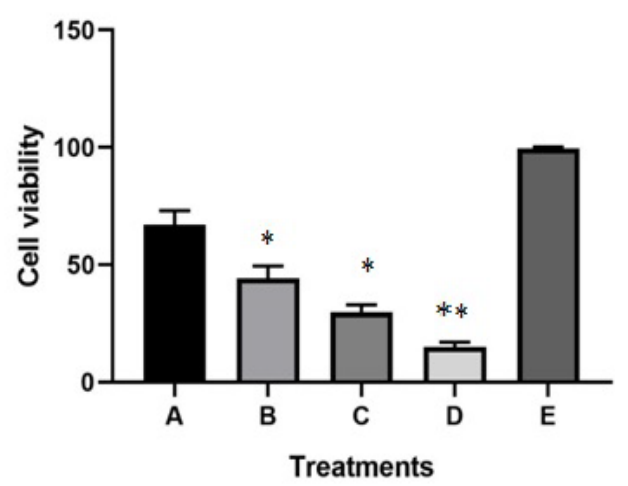

Figure 2. Results of WST-1 (cellular viability assay) in Combination Cases of Curcumin and DOX in Different Concentrations that Presented as Mean \pm standard deviation; ** show the significant difference in compared to A, B, C and E group $(\mathrm{p}<0.05)$. * show the significant differences in compared to $\mathrm{A}$ and $\mathrm{E}$ group $(\mathrm{p}<0.05) ; \mathrm{D}$, Curcumin; $20 \mu \mathrm{M} ; \mathrm{DOX} ; 5 \mu \mathrm{M}$ (concentrations); C, Curcumin; $10 \mu \mathrm{M} ; \mathrm{DOX} ; 2.5 \mu \mathrm{M}$ (concentrations); B,Curcumin; $5 \quad \mu \mathrm{M} ; \mathrm{DOX} ; 1 \mu \mathrm{M}$ (concentrations); A,Curcumin; $2.5 \mu \mathrm{M}$;DOX;0.5 $\mu \mathrm{M}$ (concentrations); E, Untrated HCT-116 cells (Control). 
WST-1 results from double combination cases are presented in Figure 2.

In the case of double combination treatments, drug concentrations were; D( Curcumin; $20 \mu \mathrm{M} ; \mathrm{DOX} ; 5 \mu \mathrm{M}$ ) C ( Curcumin; $10 \mu \mathrm{M} ; \mathrm{DOX} ; 2.5 \mu \mathrm{M}$ ), B (Curcumin; 5 $\mu \mathrm{M} ; \mathrm{DOX} ; 1 \mu \mathrm{M})$ and $\mathrm{A}$ (Curcumin; $2.5 \mu \mathrm{M}$;DOX;0.5 $\mu \mathrm{M}$ ). The E group (control) was the untreated cells which had any exposure to DOX and curcumin.

The DOX in combination with curcumin showed increased cytotoxicity compared to higher concentrations (the doses, which led to $50 \%$ of cell killed in single treatments) of each single agents. The D group had higher cytotoxic effects in compared to A,B,C and E groups $(p<0.05)$. In addition, the $C$ and $B$ group showed increased toxicity in compared to $\mathrm{A}$ and $\mathrm{E}$ groups $(\mathrm{p}<0.05)$. Indeed, in combination cases in the low concentrations of DOX and curcumin, the cellular viability were decreased in compared to each single drug treatments in the concentration which led to $50 \%$ of cell toxicity [C and D treatments had significant elevated toxicity versus to each single treatments $(p<0.05)]$.

\section{Discussion}

Amongst diverse ranges of disorders, cancer has always considered as the furthermost important condition, which affected many individuals word width. In this regards, different cancer therapeutics applied to overcome cancer cell growth $[3-8,16]$. CRC considered as one of the commonest cancers all over the worlds. In the face of innovative treatment strategies, CRC is infrequently cured because of recurrence. Numerous studies have utilized curcumin, as anti-cancer agents in numerous types of cancer, such as CRC [17]. Since, Anthracycline drugs such as DOX remain some of the most active wide-spectrum and cost-effective drugs in cancer therapy and CRC cells are resistant to anthracyclines, we evaluated the effects of curcumin in combination with DOX in CRC cells.

Based on our data DOX and curcumin in the dose dependent manner reduced the cellular viability. In combination cases in the lower concentrations of DOX and curcumin, the cellular viability were decreased in compared to each single drug treatments in the concentration which led to $50 \%$ of cell killed.

Our study assess the curcumin effects in combination with DOX, to evaluate how curcumin increase the cytotoxic effects of DOX in CRC cells. For this elevated cytotoxic effects in combination cases, it could be proposed with that fact which described by Chauhan et al. in this study , they indicated that curcumin should be considered as a harmless, non-toxic chemotherapeutic drug [7] which impedes lipooxygenase activity, impeding the cytochrome P-450 enzyme activity and promotion/progression stages of carcinogenesis. The anti-cancer properties of curcumin has been associated with arrest of cancer cells in S, G2/M cell cycle phase and apoptosis activation [7].

Recently researchers indicated that curcumin in combination with DOX was effective in sensitizing cancer cells that are resistant to DOX and in decreasing cancer cells viability. Curcumin has also been shown to induce the immuno-, hepato-, and cardioprotective characteristics of DOX [18] which is similar to our data.

Also, Meiyanto et al utilized curcumin in combination with DOX that increased the sensitivity of resistant MCF-7 cells to DOX, which was comparable to our results [19].

Other study showed that two drug (curcumin+DOX) loaded in a single nanoparticle formulation decrease the drug resistance by effects on gradual mRNA expression of MDR1 and Bcl-2 in CML blast-like K562 cells [20].

In addition, Huang et al reported that curcumin could increase the impacts of irinotecan on CRC cells by effect on cell viability and apoptosis, which is similar to our results [21].

In conclusion, it could be deduced that curcumin as natural agents can affect main carcinogenic pathways without demonstrating noticeable adverse impacts, which might be considered as perfect chemosensitizer agents in combination with DOX. In this study, we confirmed the cytotoxic effects of dietary agent's curcumin for chemosensitizing of DOX.

\section{References}

1. Comella P, Casaretti R, Sandomenico C, Avallone A, Franco L. Role of oxaliplatin in the treatment of colorectal cancer. Ther Clin Risk Manag. 2009;5(1):229-38.

2. Hsu HH, Chen MC, Baskaran R, Lin YM, Day CH, Lin YJ, Tu CC, Vijaya Padma V, Kuo WW, Huang CY. Oxaliplatin resistance in colorectal cancer cells is mediated via activation of ABCG2 to alleviate ER stress induced apoptosis. J Cell Physiol. 2018 Jul;233(7):5458-5467. doi: 10.1002/ jcp.26406. Epub 2018 Jan 23.

3. Mohammadian M, Zeynali S, Azarbaijani AF, Khadem Ansari MH, Kheradmand F. Cytotoxic effects of the newlydeveloped chemotherapeutic agents 17-AAG in combination with oxaliplatin and capecitabine in colorectal cancer cell lines. Res Pharm Sci. 2017;12(6):517-525

4. Sonowal H, Pal PB, Wen JJ, Awasthi S, Ramana KV, Srivastava SK. Aldose reductase inhibitor increases doxorubicin-sensitivity of colon cancer cells and decreases cardiotoxicity. Sci Rep. 2017;7(1):3182. Published 2017 Jun 9. doi:10.1038/s41598-017-03284-w.

5. Chauhan DP.Chemotherapeutic potential of curcumin for colorectal cancer. Curr Pharm Des. 2002;8(19):1695-706.

6. Patel BB, Gupta D, Elliott AA, Sengupta V, Yu Y, Majumdar AP. Curcumin targets FOLFOX-surviving colon cancer cells via inhibition of EGFRs and IGF-1R. Anticancer Res. 2010;30(2):319-25.

7. Chauhan DP. Chemotherapeutic potential of curcumin for colorectal cancer. Curr Pharm Des. 2002;8:1695-1706.

8. Ebrahimi Far M, Nili-Ahmadabadi A, Akbarzadeh A, et al 2017. Preparation, Characterization and Cytotoxic Effects of Pegylated Nanoliposomal Containing Carboplatin on Ovarian Cancer Cell Lines. Ind J Clin Biochem, 32, 230-234.

9. Izadi M, Ebrahimi Shahemabadi H, Kanaani L, et al. 2016. Investigation of characteristics of loaded carboplatin on the liposomal nanoparticles on the cell carcinoma of the human brain c6. Adv. Biores, 7, 113-118.

10. Poy D, Akbarzadeh A, Ebrahimi Shahmabadi H, et al. 2016. Preparation, Characterization and Cytotoxic Effects of Liposomal Nanoparticles Containing Cisplatin: An in Vitro Study. Chemical Biology \& Drug Design, 88, 568-573.

11. Esfahani MKM , et al. Pegylation of nanoliposomal paclitaxel 
enhances its efficacy in breast cancer. Tropical Journal of Pharmaceutical Research. 2014;13(8):1195-8.

12. Ahmadi L, Chiani M, et al. To evaluate the effect of formulation of Nanoarchaeosomal 6-gingerol on the growth of breast cancer MCF-7 cell line. New Cellular and Molecular Biotechnology Journal. 2015;5(19):47-52.

13. Zarei M, Norouzian D, Chiani M, Ebrahimi H, Mohammadi M. Advantages of paclitaxel-loaded nano niosomes to nanoliposomal formulation: an in vitro study. Int J Life Sci Bt \& Pharm Res. 2013;2:335-42.

14. Dadga N, Alavi E, Moftakhari Esfahani M, et al. Evaluation the cytotoxicity of nanoliposomal artemisinin on breast cancer cell line. New Cellular and Molecular Biotechnology Journal. 2014;4:99-103.

15. Zeynali M S, Mohammadian M, Kheradmand F et al. 2018. A molecular basis for the synergy between 17 allylamino 17 demethoxy geldanamycin with Capecitabine and Irinotecan in human colorectal cancer cells through VEFG and MMP-9 gene expression. Gene. pii: S0378-1119(18)31050-3.

16. Arshad Z, Rezapour-Firouzi S, Mohammadian M, et al 2018. The Sources of Essential Fatty Acids for Allergic and Cancer Patients; a Connection with Insight into Mammalian Target of Rapamycin: A Narrative Review. Asian Pac J Cancer Prev. 19(9):2391-2401.

17. Ramasamy TS, Ayob AZ, Myint HH, Thiagarajah S, Amini F. Targeting colorectal cancer stem cells using curcumin and curcumin analogues: insights into the mechanism of the therapeutic efficacy. Cancer Cell Int. 2015;15:96. Published 2015 Oct 9. doi:10.1186/s12935-015-0241-x

18. Panda AK, Chakraborty D, Sarkar I, Khan T, Sa G. New insights into therapeutic activity and anticancer properties of curcumin. J Exp Pharmacol. 2017;9:31-45. Published 2017 Mar 31. doi:10.2147/JEP.S70568.

19. Meiyanto E, Putri DD, Susidarti RA, et al. Curcumin and its analogues (PGV-0 and PGV-1) enhance sensitivity of resistant MCF-7 cells to doxorubicin through inhibition of HER2 and NF-kB activation. Asian Pac J Cancer Prev. 2014;15(1):179-184.

20. Misra R, Sahoo SK. Coformulation of doxorubicin and curcumin in poly (D, L-lactide-co-glycolide) nanoparticles suppresses the development of multidrug resistance in K562 cells. Mol Pharm. 2011; 8(3):852-866.

21. Huang YF, Zhu DJ, Chen XW, et al. Curcumin enhances the effects of irinotecan on colorectal cancer cells through the generation of reactive oxygen species and activation of the endoplasmic reticulum stress pathway. Oncotarget. 2017;8(25):40264-40275.

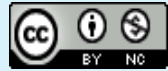

This work is licensed under a Creative Commons AttributionNon Commercial 4.0 International License. 